\title{
A STUDY OF CLINICAL PROFILE, AETIOLOGY AND OUTCOME OF PATIENTS PRESENTING WITH PLEURAL EFFUSION
}

\author{
Akshay M. Hiremath1, Dharma U. Shetty2, Patre Rachita ${ }^{3}$ \\ ${ }^{1}$ Assistant Professor, Department of Pulmonary Medicine, Jagadguru Jayadeva Murugarajendra Medical College, Davangere, \\ Karnataka, India. \\ 2Postgraduate Student, Department of Pulmonary Medicine, Jagadguru Jayadeva Murugarajendra Medical College, Davangere, \\ Karnataka, India. \\ ${ }^{3}$ Senior Resident, Department of General Medicine, Jagadguru Jayadeva Murugarajendra Medical College, Davangere, Karnataka, \\ India.
}

\begin{abstract}
\section{BACKGROUND}

Pleural effusion is excess fluid that accumulates in the pleural space which is always abnormal and indicates the presence of an underlying disease. Excessive amounts of such fluid can impair breathing by limiting the expansion of the lungs during respiration. Our study is an etiological study of pleural effusion by conventional methods, such as clinical presentation along with radiological, biochemical and cytological correlation in J.J.M. Medical College attached Hospitals. The purpose of article is to study the etiological profile, clinical profile and outcome of patients admitted with pleural effusion.
\end{abstract}

\section{MATERIALS AND METHODS}

This was a prospective observational study of consecutively admitted patients with pleural effusion in Department of Pulmonary Medicine, J.J.M Medical College, Davangere. The study was carried out on 50 patients with pleural effusions. Detailed history, physical examination was done along with correlation of radiological, biochemical and cytological investigation. Sample size taken for convenience.

\section{RESULTS}

In this prospective observational study of 50 patients with pleural effusion, the mean age was $45.4 \pm 17.67$ years and two thirds were men. The three most common causes of pleural effusion in this study were tuberculosis (60\%) followed by empyema (12\%), transudative $(10 \%)$ and parapneumonic effusion (10\%) respectively. Among the transudative pleural effusion, congestive heart failure was most common cause. The patients with TB were young. The most common symptoms encountered by them were cough (83.33\%), followed by fever (56.67\%) and chest pain (36.67\%). Empyema was the $2^{\text {nd }}$ most common cause of pleural effusion in the study, cough was the predominant symptom (83.33\%), followed by chest pain (50\%) and breathlessness (50\%) in the study population. Right sided effusion was most common with male to female ratio of 1.94:1. Pleural fluid ADA proved to be a good diagnostic indicator in TB effusion. ADA more than $70 \mathrm{IU} / \mathrm{L}$ was associated with nearly half of Tubercular effusions. Empyema was most commonly associated with high total cell counts, with predominant neutrophils, pleural fluid glucose $<40 \mathrm{mg} \%$, Pleural LDH to serum LDH ratio $>2$.

\section{CONCLUSION}

In pleural effusion, TB effusion remained to be the most common cause, which was diagnosed symptomatically, diagnostically with the aid of Lymphocyte: Neutrophil ratio, colour of pleural fluid and ADA levels, LDH, pleural fluid glucose. Total count helped in diagnosis of empyema and parapneumonic effusions. Congestive heart failure remained to be most common cause of transudative effusion, managed conservatively. Early diagnosis, early initiation of antitubercular drugs in TB effusion, early intervention and treatment like ICD procedures in cases of empyema and parapneumonic effusion showed improvement and signs of recovery in pleural effusion patients.

\section{KEY WORDS}

ADA- Adenosine Deaminase, LDH- Lactate Dehydrogenase, TB - Tuberculosis, PE- Pleural Effusion, PPE- Parapneumonic Effusion, EMP- Empyema, MAL- Malignancy, TRANS- Transudative Effusion

HOW TO CITE THIS ARTICLE: Hiremath AM, Shetty DU, Rachita P. A study of clinical profile, aetiology and outcome of patients presenting with pleural effusion. J. Evolution Med. Dent. Sci. 2019;8(08):494-499, DOI: 10.14260/jemds/2019/110

'Financial or Other Competing Interest': None.

Submission 10-12-2018, Peer Review 08-02-2019,

Acceptance 14-02-2019, Published 25-02-2019.

Corresponding Author:

Dr. Akshay M. Hiremath,

\#311/1A, Shivaprakash Nursing Home,

P. J. Extension, Pavillion Road,

Davangere-577004, Karnataka, India.

E-mail: akshaymh03@gmail.com

DOI: $10.14260 /$ jemds $/ 2019 / 110$

\section{(c) $(\mathrm{P})($}

\section{BACKGROUND}

The pleural space is bounded by two membranes, the visceral pleura covering the lung and the parietal pleura covering the chest wall and diaphragm.

Into this space, normal liquid and protein enter from the systemic circulation and are removed by the parietal pleural lymphatics. Pleural pressure is sub atmospheric and ensures inflation of the lung. Because the mesothelial boundaries are leaky, excess liquid can move across into this lower-pressure, high-capacitance space and accumulate as a pleural effusion. ${ }^{1}$

Pleural effusion is the abnormal accumulation of fluid in the pleural space. A pleural effusion is always abnormal and 
indicates the presence of an underlying disease. ${ }^{2}$ Patients most commonly present with exertional breathlessness, dry cough \& pleuritic chest pain. Patients with pleural effusion have higher morbidity and mortality than patients without pleural effusion. ${ }^{3}$

Pleural effusions are common finding and of highly diverse aetiologies, with higher incidence of effusions secondary to non-infective pathology in the western studies compared to infective pathology in India. ${ }^{4}$ Most of the patients are admitted to the hospital for conditions other than pleural disease, the pleura is often secondarily affected by pulmonary parenchymal disorders and other organ system dysfunction. ${ }^{5}$

Depending on the protein and lactate dehydrogenase (LDH) concentrations of the pleural fluid, these effusions can be categorized as exudates or transudates. Exudative pleural effusions meet at least two of the following criteria, whereas transudative effusions meet none (Light's criteria: pleural fluid protein-to-serum protein ratio of more than 0.5 , pleural fluid LDH-serum LDH ratio of more than 0.6, and pleural fluid LDH more than two thirds of the upper normal limit for serum). ${ }^{1}$

The etiological distribution of PE depends on the geographic region, patients age \& advances in the diagnosis and treatment of underlying cause. Determining the etiological \& clinical profile of PE helps in adoption of regionally optimized diagnosis \& therapeutic approach. ${ }^{6}$

Tuberculosis is the most common cause of pleural effusion in India when compared to the Western countries where malignancy and parapneumonic effusions are more common. ${ }^{7}$

The diagnostic evaluation of pleural effusion includes chemical and microbiological studies as well as cytological analysis, which can provide further information about the aetiology of the disease process. Transudative effusions are usually managed by treating the underlying medical disorder. However, a large, refractory pleural effusion, whether a transudate or exudate, must be drained to provide symptomatic relief. Management of exudative effusion depends on the underlying aetiology of the effusion. Malignant effusions are usually drained to palliate symptoms and may require pleurodesis to prevent recurrence. ${ }^{8}$

Hence an attempt to study the aetiology, clinical profile and outcome of patients presenting with PE in the hospital is taken up which may help in adoption of regionally optimized diagnosis \& therapeutic approach.

\section{Objectives of the Study}

To study the aetiological profile, clinical profile and outcome of pleural effusion

\section{MATERIALS AND METHODS Methodology}

Inpatients of Department of Pulmonary Medicine, attached to JJM Medical College, with pleural effusion, fulfilling the inclusion \& exclusion criteria were included in the study after obtaining written informed consent. Demographic data, history, clinical examination and details of investigations like routine blood investigations, sputum examination, chest $\mathrm{X}$ rays and pleural fluid analysis. The pleural fluid will be analysed for cell count, cell type, protein, glucose, ADA, PH, $\mathrm{LDH}$, Cholesterol levels and ultrasound thorax, CT thorax will be done case per case basis). Sample size taken for convenience.

\section{Source of Data}

The study was be conducted in JJM medical college, Davangere, Karnataka on patients with pleural effusions admitted in the medical wards.

\section{Method of Collecting Data \\ Study Design}

A prospective observational study.

\section{Place of Study}

JJM Medical College, Davangere.

\section{Duration of Study}

$2014-2016$

\section{Sampling Technique}

Convenient sampling.

\section{Sample Size}

50 patients.

\section{Inclusion Criteria}

- Both male and female patients with age more than 18 years presenting with clinical features of pleural effusion.

- More than 24 hours stay in hospital.

\section{Exclusion Criteria}

Patients who haven't given consent.

\section{Statistical Method}

Appropriate statistical method was followed. (Measures of central tendency and dispersion, Graphical representation of data was done using IBM SPSS Statistics v20.0).

\section{RESULTS}

\section{Demographic Data}

In this observational study, fifty consecutive patients with pleural effusions were studied in which 33 were males and 17 were females. The mean age was $45.4 \pm 17.67$ years. The male to female ratio was 1.94:1 and nearly two thirds were men.

\section{Aetiology}

In this study patients with pleural effusion were classified as transudative ( 5 out of 50 ) and exudative pleural effusion (45 out of 50) based on Lights criteria. These were further classified (Graph-1) based on aetiology, clinical profile and outcome as-

\section{- Exudative pleural effusions-90\%:}

The majority were tubercular in origin $(60.0 \%)$, followed by empyema (12\%), parapneumonic effusion (10\%) respectively, malignant effusion (6\%), others (which includes pancreatic pleural effusion) (2\%).

- Transudative pleural effusions-10\%:

Among five transudative pleural effusion majority were due to CCF ( 3 out of 5), followed by one effusion due to hypoproteinaemia and hepatic hydrothorax. 


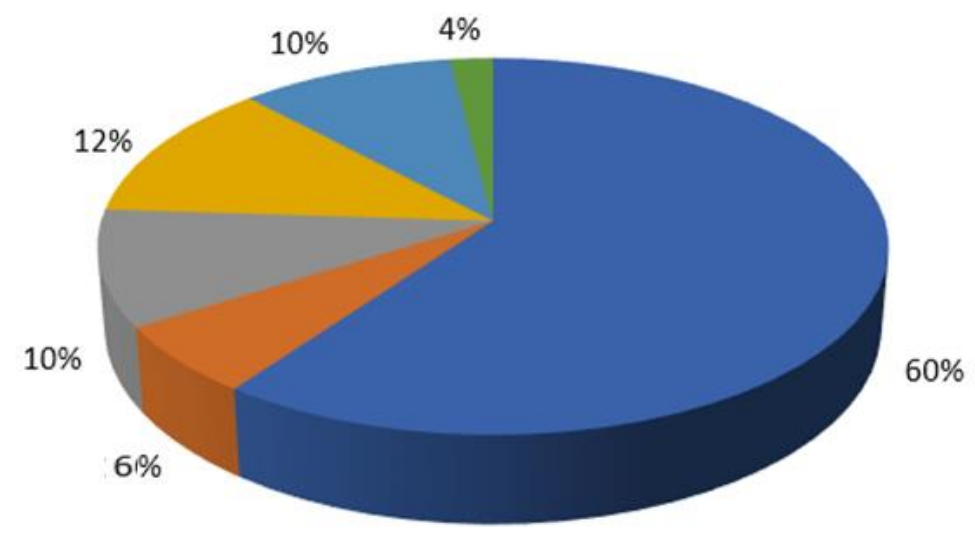

- Tuberculosis

Malignancy

arapneumonic effusion

- Empyema

- Transudative effusion

athers

\section{Graph 1. Etiological Classification of Effusion}

\section{Age and Aetiology}

Around $66.6 \%$ Patients with tubercular effusion were of age between 21 to 40 years than those with other causes of effusion, especially malignant effusion where $66.66 \%$ of patients were of age $>60$ years. So, the patients with TB were younger than the patients with malignancy.

\section{Presenting Symptoms}

Patients with tubercular effusion presented predominantly with cough (83.33\%), followed by fever (56.67\%) and chest pain (36.67\%). In empyema patients, cough was the predominant symptom (83.33\%), followed by chest pain (50\%) and breathlessness (50\%).

Parapneumonic effusion cough (100\%) followed by fever (80\%) and in transudative effusion cough (100\%) followed by breathlessness (60\%) were major symptoms respectively.

\begin{tabular}{|c|c|c|c|c|c|c|c|}
\hline \multirow{2}{*}{ Symptoms } & \multicolumn{6}{|c|}{ Aetiology } & \multirow{2}{*}{ Total } \\
\hline & TB & MAL & PPE & EMP & TRANS & OTHER & \\
\hline Cough & $25(83.33 \%)$ & $3(100 \%)$ & $5(100 \%)$ & $5(83.33 \%)$ & $5(100 \%)$ & 0 & 43 \\
\hline Sputum & $12(48 \%)$ & $1(33.33 \%)$ & $2(40 \%)$ & $3(60 \%)$ & $4(80 \%)$ & 0 & 22 \\
\hline Dry & $3(52 \%)$ & $2(66.67 \%)$ & $3(60 \%)$ & $2(40 \%)$ & $1(20 \%)$ & 0 & 21 \\
\hline Fever & $17(56.67 \%)$ & 0 & $4(80 \%)$ & $2(33.33 \%)$ & $1(20 \%)$ & 0 & 24 \\
\hline Chest Pain & $11(36.67 \%)$ & $1(33.33 \%)$ & $4(80 \%)$ & $3(50 \%)$ & $1(20 \%)$ & $1(100 \%)$ & 21 \\
\hline Breathlessness & $18(60 \%)$ & $1(33.33 \%)$ & $1(20 \%)$ & $3(50 \%)$ & $4(80 \%)$ & $1(100 \%)$ & 27 \\
\hline Haemoptysis & $1(3.33 \%)$ & 0 & 0 & $1(16.67 \%)$ & 0 & 0 & 2 \\
\hline
\end{tabular}

\section{Size of Effusion}

Large effusions (Defined as pleural effusion occupying greater than 2/3rd of hemithorax on chest X-ray) were seen in malignant effusion. In rest of the aetiologies, small to moderate effusion classified as 'not large effusions / small effusions' were seen.

Loculated pleural effusion which were seen in $3(6 \%)$ patients were included in 'not large effusion / small effusions. Among these 3 patients, 1 (33.33\%) was loculated tubercular effusion and 2 (66.67\%) were loculated empyema.

\begin{tabular}{|c|c|c|c|}
\hline \multirow{2}{*}{ Aetiology } & \multicolumn{3}{|c|}{ X-Ray Findings } \\
\cline { 2 - 4 } & Not Large/Small & Large & Combined \\
\hline Tuberculosis & $28(93.33 \%)$ & $2(6.67 \%)$ & 30 \\
\hline Malignancy & 0 & $3(100 \%)$ & 3 \\
\hline Parapneumonic Effusion & $4(80 \%)$ & $1(20 \%)$ & 5 \\
\hline Empyema & $6(100 \%)$ & 0 & 6 \\
\hline Transudative Effusion & $4(80 \%)$ & $1(20 \%)$ & 5 \\
\hline Others Table 2. Size of The Effusion and Aetiology & 0 & 1 \\
\hline Total & $1(100 \%)$ & $\mathbf{0 7}(14 \%)$ & $\mathbf{5 0 0}(10)$ \\
\hline
\end{tabular}

\section{Pleural Fluid Appearance}

Majority of the effusions were straw coloured especially tubercular (80\%) and parapneumonic effusion (60\%). Haemorrhagic effusions were seen most commonly in malignant pleural effusions (100\%). Empyema was associated with pus (100\%). 


\section{Total Cell Counts}

Most effusions had a total cell count between 1000 to 5000 cells $/ \mathrm{mm}^{3}$. Counts greater than $5,000 / \mathrm{mm}^{3}$ were seen predominantly in empyema (83.33\%) and parapneumonic effusion (60\%).

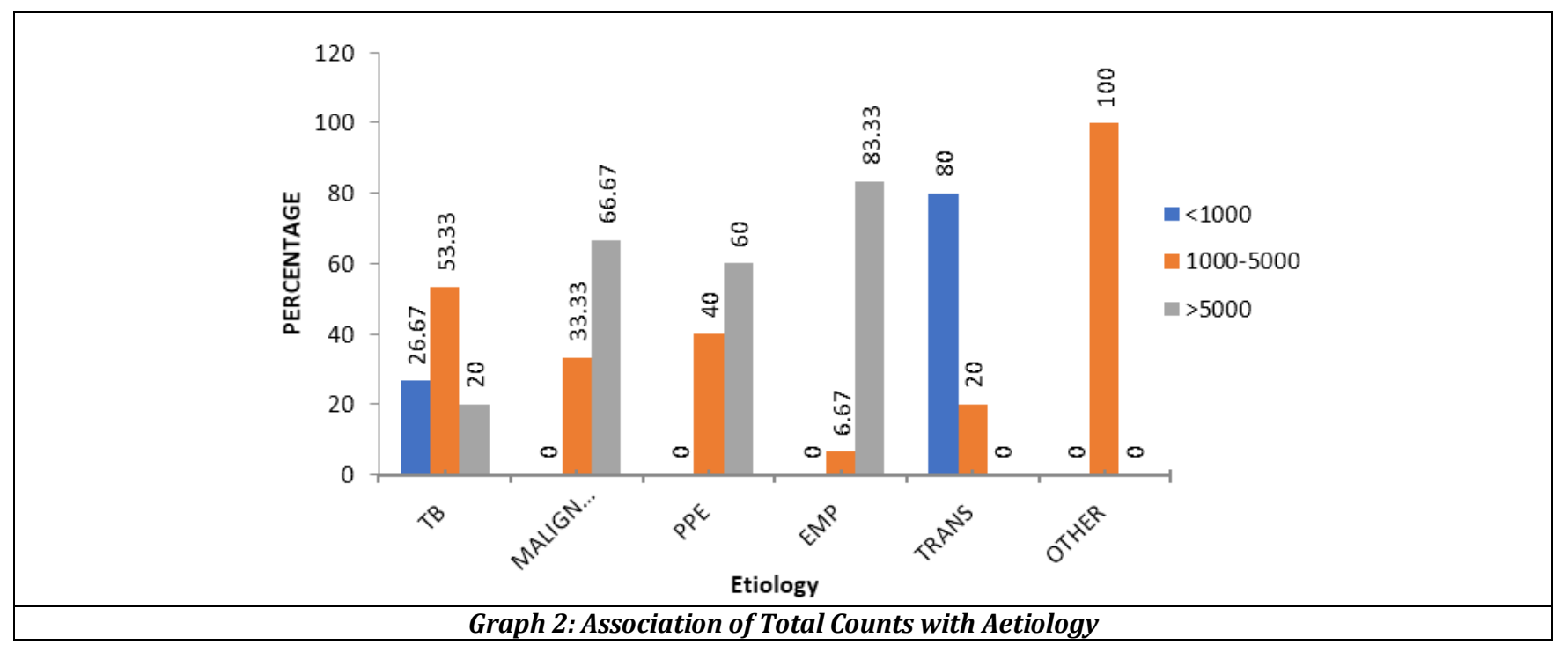

\section{Lymphocyte to Neutrophil Ratio}

20 effusions out of 30 effusions (66.67\%) were lymphocyte predominant in confirmed tubercular effusion. Majority of neutrophil predominant effusion were Parapneumonic effusion (80\%) and empyema (83.33\%).

\begin{tabular}{|c|c|c|c|c|c|c|c|}
\hline \multirow{2}{*}{$\begin{array}{c}\text { LN Ratio \& } \\
\text { Aetiology }\end{array}$} & TB (n=30) & MAL (n=3) & PPE (n=5) & EMP (n=6) & TRANS (n=5) & OTHER (n=1) & \multirow{2}{*}{ Total (n=50) } \\
\hline$<75 \%$ & $10(33.33 \%)$ & 0 & $4(80 \%)$ & $5(83.33 \%)$ & $2(40 \%)$ & $1(100 \%)$ & 22 \\
\hline$>75 \%$ & $20(66.67 \%)$ & $3(100 \%)$ & $1(20 \%)$ & $1(16.67 \%)$ & $3(60 \%)$ & 0 & 28 \\
\hline \multicolumn{7}{|c|}{ Table 3. Lymphocyte Predominant Effusion with Aetiology } \\
\hline
\end{tabular}

\section{Pleural LDH to Serum LDH Ratio and Aetiology}

The ratio of pleural fluid LDH to serum LDH was more than 2 in $100 \%$ and $40 \%$ of patients with empyema and parapneumonic effusion respectively. Patients with tubercular effusion had a ratio greater than 2 in $23.33 \%$ of patients. Pleural LDH to ser um LDH ratio was lesser than 0.6 in all of transudative effusions (100\%).

\begin{tabular}{|c|c|c|c|c|c|c|c|}
\hline \multirow{2}{*}{$\begin{array}{c}\text { Pleural LDH/ } \\
\text { Serum LDH Ratio }\end{array}$} & TB & MAL & PPE & EMP & TRANS & OTHER & \multirow{2}{*}{ Total } \\
\cline { 2 - 8 } & $4(13.33 \%)$ & $1(33.33 \%)$ & 0 & 0 & $5(100 \%)$ & 0 & 10 \\
\hline$<0.6$ & $11(36.67 \%)$ & $1(33.33 \%)$ & $1(20 \%)$ & 0 & 0 & $1(100 \%)$ & 14 \\
\hline $0.6-1.0$ & $8(26.67 \%)$ & $1(33.33 \%)$ & $2(40 \%)$ & 0 & 0 & 0 & 11 \\
\hline $1.0-2.0$ & $7(23.33 \%)$ & 0 & $2(40 \%)$ & $6(100 \%)$ & 0 & 0 & 15 \\
\hline$>2.0$ & $\mathbf{3 0}(\mathbf{1 0 0} \%)$ & $\mathbf{3 ( 1 0 0 \% )}$ & $\mathbf{5 ( 1 0 0 \% )}$ & $\mathbf{6 ( 1 0 0 \% )}$ & $\mathbf{5 ( 1 0 0 \% )}$ & $\mathbf{1 ( 1 0 0 \% )}$ & $\mathbf{5 0}$ \\
\hline Total & Table 4. Pleural LDH / Serum LDH Ratio and Aetiology \\
\hline
\end{tabular}

\section{Pleural Fluid Glucose Level}

The majority of pleural fluid glucose levels were between $40-100 \mathrm{mg} / \mathrm{dl}$ in tubercular effusions. All of the empyema's had pleural fluid glucose level less than $40 \mathrm{mg} / \mathrm{dl}$ (100\%). Around $20 \%$ of parapneumonic effusion, $6.67 \%$ of Tubercular effusion had pleural fluid glucose levels less than $40 \mathrm{mg} / \mathrm{dl}$.

\section{Pleural Fluid Adenosine Deaminase (ADA)}

In our study 14 patients (46.67\%) with tubercular effusion had a ADA level more than 70I U/L, 15 patients (50\%) with ADA level between 30-70 IU/L and 1 patient (3.33\%) \% showed a level of less than $30 \mathrm{IU} / \mathrm{L}$.

\begin{tabular}{|c|c|c|c|c|c|c|}
\hline \multirow{2}{*}{ ADA (IU/L) } & TB & MAL & PPE & EMP & TRANS & Other \\
\cline { 2 - 7 } & $1(3.33 \%)$ & $2(66.67 \%)$ & $2(40 \%)$ & $3(50 \%)$ & $4(80 \%)$ & $1(100 \%)$ \\
\hline$<30$ & $15(50.00 \%)$ & $1(33.33 \%)$ & $3(60 \%)$ & $2(33.33 \%)$ & $1(20 \%)$ & 0 \\
\hline $30-70$ & $14(46.67 \%)$ & 0 & 0 & $1(16.67 \%)$ & 0 & 0 \\
\hline$>70$ & $\mathbf{3 0}$ & $\mathbf{3}$ & $\mathbf{5}$ & $\mathbf{6}$ & $\mathbf{5}$ & $\mathbf{1}$ \\
\hline Total & \multicolumn{7}{|c|}{ Table 5. ADA with Aetiology } \\
\hline
\end{tabular}




\section{Outcome}

Patients admitted with TB effusion (30 patients) empyema ( 6 patients) parapneumonic effusions ( 5 patients), transudative effusion (5 patients) showed improvement after clinical, radiological diagnosis and treatment. All the patients were followed and managed accordingly.

\section{DISCUSSION}

In this study of 50 patients with pleural effusion, the mean age was $45.4 \pm 17.67$ years and nearly two thirds were men. Tubercular effusion affects most commonly young and the mean age was 38.33 years, consistent with Luis Valdes et $\mathrm{al}^{9}$ (34 years) and S.K. Sharma et $\mathrm{al}^{10}$ (33 years). Earlier studies done in United States by Epstein et $\mathrm{al}^{11}$ and Aho $\mathrm{K}$ et al.12 Showed a mean age of 54 and 28 years respectively. TB effusion is associated with cough and fever as the most common presenting symptom, in comparison with the studies done earlier by Moudgil et al ${ }^{13}$ and Berger H.W ${ }^{14}$ et al in which most common symptom was fever $(82.06 \%)$ followed by cough $(72.46 \%)$ and chest pain $(31.8 \%)$.

Malignant effusions were seen in older age group around 60 years (mean 58 years) compared to study by Sharma et al (mean age 47 years). It is how ever well known that Indian patients with malignancy are 15 years younger as compared to the West as seen by Pathak et al. ${ }^{15}$ Patients with malignant effusion had cough (100\%) followed by dyspnoea (33.33\%) as common symptoms similar to a study by Chernov B et al, where cough (62\%) was the predominant symptom. Massive effusion with haemorrhagic pleural fluid is in $100 \%$ of malignant effusion $100 \%$ of malignant effusions as compared to a study done by Maher et al ${ }^{16}$ (55\%).

$66.67 \%$ of TB effusions and $100 \%$ of malignant effusions had lymphocyte predominance. Our result was similar to the study done by Valdes L et al ${ }^{17}$ where they have encountered neutrophil predominant tuberculous effusion in only $6.7 \%$ of patients. In tubercular effusion pleural fliid glucose were between $40-100 \mathrm{mg} / \mathrm{dl}$ consistent with the earlier observation by Light. 18

Although a pleural fluid ADA above $70 \mathrm{IU} / \mathrm{L}$ is definitive of tuberculosis, diagnosis should be considered if the pleural fluid ADA is between $40 \mathrm{IU} / \mathrm{L}$ and $70 \mathrm{IU} / \mathrm{L}$. In tubercular, pleural effusion pleural fluid Adenosine de-aminase lelvel (ADA) has got a good diagnostic index after excluding other causes of raised ADA levels. But different authors have used different cut off levels for pleural fluid ADA ranging between $33 \mathrm{IU} / \mathrm{L}$ to $50 \mathrm{IU} / \mathrm{L}$.

In this study $96.67 \%$ of tubercular effusion had ADA of $>30$ IU/L and ADA more than 70 IU/L was associated with nearly half of Tubercular effusions. Studies done in the West demonstrate pleural fluid ADA more than $70 \mathrm{IU} / \mathrm{L}$, by Valdes et $\mathrm{al}^{19}$ and Burgess et $\mathrm{al}^{20}$ which is consistent with our study which showed a mean of $83.6 \mathrm{IU} / \mathrm{L}$. The mean ADA were high in the two Indian studies done by Rajendra Prasad et al21, and Gilhotra et al22 with the mean ADA level ranging between 76.8 $\pm 23.8 \mathrm{IU} / \mathrm{L}-95.8 \pm 57.5 \mathrm{IU} / \mathrm{L}$.

In 2 out 3 patients pleural fluid were positive for malignant cytology in consistent with the studies showing the malignant cytology ranging from $40 \%$ to $87 \%$ by Bueno CE et al. ${ }^{23}$ Though it is consistent with observed literature, the numbers are too small to draw a definite conclusion. In carcinoma lung patient where pleural fluid malignant cytology was negative it was further investigated for sputum malignant cytology (Which was negative in that patient) and further subjected to BAL fluid / endobronchial biopsy and found to be positive for malignant cells. Thus, signifying the importance of role of BAL fluid / endobronchial biopsy in patients with negative malignant cytology.

In terms of outcome, patients with TB pleural effusion (30 patients) who were treated with Antitubercular treatment improved, substantiated by clinical and radiological evidences. $^{24}$ Whereas empyema's (6 patients) and parapneumonic effusions (5 patients) improved with interventions like Intercostal drainage tube insertion, streptokinase infusion to break adhesions and loculation, along with appropriate antibiotic treatment. ${ }^{25}$ Transudative effusions ( 5 patients) showed improvement with conservative line of management especially Congestive heart failure. ${ }^{26}$ In malignant effusions, thoracentesis and Pleurodesis were done for symptomatic betterment and were followed up for further treatment and management. ${ }^{27}$ Also a incidental case of pancreatic pleural effusion (Pleural effusion due to pseudocyst pancreas) was diagnosed and was treated accordingly. ${ }^{28}$

\section{Study Highlights}

\begin{tabular}{|c|c|c|}
\hline \multicolumn{2}{|c|}{$\begin{array}{l}\text { Total Patients } \\
\text { Male } \\
\text { Female } \\
\text { Mean Age } \\
\text { M.C. Complaint } \\
\end{array}$} & $\begin{array}{c}50 \\
33(66 \%) \\
17(34 \% \\
45.4+-17.6 \\
\text { Cough }\end{array}$ \\
\hline & Transudative & Exudative \\
\hline Total Cases & $10 \%(5$ out of 50$)$ & $90 \%(45$ out of 50$)$ \\
\hline M.C. Cause & $\mathrm{CCF}$ & Tubercular \\
\hline LDH $>0.6$ & $0 \%$ & $88.89 \%$ \\
\hline $\mathrm{ADA}>40$ & $0 \%$ & $62.2 \%$ \\
\hline $\begin{array}{c}\text { L/N RATIO > } \\
0.75 \\
\end{array}$ & $60 \%$ & $55.56 \%$ \\
\hline $\begin{array}{l}\text { Improved } \\
\text { Outcome }\end{array}$ & $100 \%$ & $90 \%$ \\
\hline
\end{tabular}

\section{CONCLUSION}

- In our study, exudative effusion remained the most common cause of pleural effusion. Tubercular effusion proved to be the commonest aetiology of all exudative effusions whereas congestive cardiac failure remains commonest cause among transudative effusions.

- Massive effusion with haemorrhagic pleural fluid was commonly associated with malignant effusion while small to moderate effusions with straw colour pleural fluid is associated Tubercular effusion and empyema cases presented with pus.

- Effusion was most common in males compared to females, with mean age of 45.4 years and right side was more compared to left.

- Empyema was most commonly associated with high total counts. Tubercular effusion was associated with lymphocytic predominant effusion whereas neutrophilic dominant effusion included empyema and parapneumonic effusion.

- Pleural fluid, with low glucose $(<40 \mathrm{mg} / \mathrm{dl})$ was seen predominantly in empyema and followed by parapneumonic effusions. 
- Pleural LDH to serum LDH ratio >2 was seen in empyema and parapneumonic effusions indicating poor prognosis.

- A pleural fluid ADA more than $70 \mathrm{IU} / \mathrm{L}$ was associated with nearly half of Tubercular effusions, whereas others with ADA levels between 30 to 70 IU/L along with clinicoradiological findings increased the chances of a tubercular effusion, thus proving diagnostic importance of ADA in TB effusions.

- Early initiation Antitubercular drugs in TB pleural effusion, early intervention and treatment in cases of empyema and parapneumonic effusion showed improvement and signs of recovery.

\section{Limitations of study}

1. Adequate samples couldn't be sent for cytological examination in a suspected case of malignant effusion.

2. Pleural biopsy was not used in diagnosis.

3. There were inadequate number of cases to comment on the role of malignant cytology in diagnosing malignant effusion.

\section{REFERENCES}

[1] Broaddus CV, Light RW. Murray \& Nadel's Textbook of Respiratory Medicine. $6^{\text {th }}$ edn. Elsevier Health Sciences 2015.

[2] Grippi MA, Elias JA, Fishman J, et al. Fishman's pulmonary diseases and disorders. Disorders of the pleural space. Part - 9. Non-malignant pleural effusion. Chapter - 76. 5th edn. New York: McGraw-Hill Education 2015: p. 1164.

[3] Khan J, Ellis ME. Anaerobic bacterial pneumonia, lung abscess, pleural effusion/empyema. In: Ellis ME, edr. Infectious disease of the respiratory tract. Cambridge: Cambridge University Press 1997: p. 358-73.

[4] Duke J, Good J, et al. Frontline assessment of common pulmonary presentations. Snowdrift Pulmonary Foundation, Inc., 2001, 1 Nov, 2009. <http://www.nlhep.org/books/asmnt_cmn_pulmryPr sntn.pdf>.

[5] Heffner JE, Klein JS. Recent advances in the diagnosis and management of malignant pleural effusions. Mayo Clin Proc 2008;83(2):235-50.

[6] Bhalla A, Jajoo AN. Aetiological distribution of pleural effusions in rural hospital. The Indian Practitioner 1998;51(7):517-21.

[7] Maldhure BR, Bedarkar SP, Kulkarni HR, et al. Pleural biopsy and adenosine deaminase in pleural fluid for the diagnosis of tubercular pleural effusion. Ind J Tuberculosis 1994;41:161-5.

[8] Karkhanis VS, Joshi JM. Pleural effusion: diagnosis, treatment and management. Open Access Emergency Medicine 2012;4:31-52.

[9] Valdes L, Alvarez D, Valle JM, et al. The etiology of pleural effusion in an area with high incidence of tuberculosis. Chest 1996;109(1):158-62.

[10] Sharma SK, Suresh V, Mohan A, et al. A prospective study of sensitivity and specificity of adenosine deaminase estimation in the diagnosis of tuberculosis pleural effusion. Indian J Chest Dis Allied Sci 2001;43(3):149-55.
[11] Epstein DM, Kline LR, Albelda SM, et al. Tuberculous pleural effusions. Chest 1987;91(1):106-9.

[12] Aho K, Brander E, Patiala J. Studies for primary drug resistance in tuberculous pleurisy. Scand J Respir Dis Suppl 1968;63:111-4.

[13] Moudgil H, Sridhar G, Leitch AG. Reactivation disease: the commonest form of tuberculous pleural effusion in Edinburgh, 1980-1991. Respir Med 1994;88(4):301-4.

[14] Berger HW, Mejia E. Tuberculous pleurisy. Chest 1973;63(1):88-92.

[15] Pathak AK, Bhutani M, Mohan A, et al. Non Small Cell Lung Cancer (NSCLC): current status and future prospects. Indian J of Chest Dis and Allied Sci 2004;46(3):191-203.

[16] Maher GG, Berger HW, et al. Massive pleural effusion: and non-malignant causes in 46 patients. Am Rev Respir Dis 1972;105(3):458-60.

[17] Valdes L, San Jose E, Alvarez D, et al. Diagnosis of tuberculous pleurisy using the biologic parameters adenosine deaminase, lysozyme and interferon gamma. Chest 1993;103(2):458-65.

[18] Light RW, Erozan YS, Ball WC Jr. Cells in Pleural fluid: their value in differential diagnosis. Arch Intern Med 1973;132(6):854-60.

[19] Valdes L, Alvarez D, San Jose E, et al. Tuberculous pleurisy: a study of 254 patients. Arch Intern Med 1998;158(18):2017-21.

[20] Burgess LJ, Maritz FJ, Le Roux I, et al. Use of adenosine deaminase as a diagnostic tool for tuberculous pleurisy. Thorax 1995;50(6):672-4.

[21] Prasad R, Tripathi RP, Mukerji PK, et al. Adenosine deaminase activity in pleural fluid - a diagnostic test of tuberculous pleueal effusion. Indian J Chest Dis Allied Sci 1992;34(3):123-6.

[22] Gilhotra R, Seghal S, Jindal SK, et al. Pleural biopsy and adenosine deaminase enzyme activity in effusions of different aetiologies. Lung India 1989;7(3):122-4.

[23] Bueno CE, Clemente GM, Castro BC, et al. Cytologic and bacteriologic analysis of fluid and pleural biopsy specimens with Cope's needle. Study of 414 patients. Arch Intern Med 1990;150(6):1190-4.

[24] Ajmal B, Ijaz K, Mahmood KT, et al. Management of tuberculous pleural effusion. J Biomed Sci and Res 2011;3(1):302-7.

[25] Hamm H, Light RW. Parapneumonic effusion and empyema. Eur Respir J 1997;10(5):1150-6.

[26] Light RW. Transudative pleural effusions. Chapter -9. In: Light's Text book of pleural diseases. $5^{\text {th }}$ edn. Philadelphia: Lippincott Williams \& Wilkins 2007: p. 122.

[27] Muduly DK, Deo SVS, Subi TS, et al. An update in the management of malignant pleural effusion. Indian J Palliate Care 2011;17(2):98-103.

[28] Kaye MD. Pleuropulmonary complications of pancreatitis. Thorax 1968;23(3):297-306. 